\title{
DINAMIKA POPULASI PADA EKOSISTEM MANGROVE
}

\author{
Hajar $^{1}$, J. W. Puspita ${ }^{2}$, N. Nacong ${ }^{3}$, dan Ridwan ${ }^{4}$ \\ 1,2,3,4Program Studi Matematika Jurusan Matematika FMIPA Universitas Tadulako \\ Jalan Soekarno-Hatta Km. 09 Tondo, Palu 94118, Indonesia. \\ 1hajar.20041990@gmail.com, 2juni.wpuspita@yahoo.com,3nasrianacong@gmail.com, 4ridwan@gmail.com
}

\begin{abstract}
Mangrove cultivation is an effort to minimize damage to marine ecosystems and the surrounding environment when a tsunami occurs. The existence of mangrove ecosystems must be protected and conserved in a sustainable manner. Uca crabs have an important role in the food chain in the mangrove ecosystem. This research aims to study the interaction between the mangrove population and the Uca crab population in the mangrove ecosystem through a mathematical model approach. We obtained four critical points of the model has been constructed. Three critical points of the mathematical model exists unconditionally but unstable. While the fourth critical point which describes the condition of the coexistence of the mangrove and Uca crab populations can be guaranteed the local stability if the stability conditions are met. This indicates that the presence of the Uca crab population can preserve the mangrove ecosystem. Numerical simulation is given to support the analytical results.
\end{abstract}

Keywords : Existence, Mangrove Ecosystem, Uca Crab, Stability

\section{ABSTRAK}

Budidaya mangrove merupakan salah satu upaya untuk meminimalisir kerusakan ekosistem laut dan lingkungan sekitarnya saat terjadi tsunami. Eksistensi ekosistem mangrove perlu dijaga dan dilestarikan secara berkelanjutan. Kepiting Uca memiliki peranan penting pada rantai makanan yang berlangsung dalam ekosistem mangrove. Penelitian ini bertujuan mengkaji interaksi antara populasi mangrove dan populasi kepiting Uca dalam ekosistem mangrove melalui pendekatan model matematika. Kami memperoleh empat titik kritis dari model yang telah dibangun. Tiga titik kritis dari model matematika eksis tanpa syarat, namun tidak stabil. Sedangkan titik kritis keempat yang menggambarkan kondisi koeksistensi populasi mangrove dan kepiting Uca dapat dijamin kestabilan lokalnya jika syarat kestabilannya terpenuhi. Hal ini mengindikasikan bahwa kehadiran populasi kepiting Uca dapat menjaga kelestarian ekosistem mangrove. Simulasi numerik diberikan untuk mendukung hasil analitik.

Kata Kunci : Eksistensi, Ekosistem mangrove, Kepiting Uca, Kestabilan 


\section{PENDAHULUAN}

Akhir-akhir ini masyarakat Indonesia bahkan dunia dikagetkan dengan berbagai bencana alam yang terjadi di Indonesia. Salah satu bencana alam yang menyedot perhatian masyarakat adalah tsunami. Tercatat, di tahun 2018 terdapat tiga wilayah NKRI yang mengalami tsunami yaitu Lombok, Palu dan Banten. Bencana ini menimbulkan kerugian dalam berbagai aspek kehidupan. Salah satu upaya untuk meminimalisir kerugian yang ditimbulkan oleh tsunami adalah dengan membuat benteng alami pantai menggunakan Green Belt Mangrove (GBM). GBM telah terbukti secara teoritik mampu meredam amplitudo gelombang yang melewati GBM (Sudarmoyo dkk, 2018). Green Belt Mangrove (GBM) yang membentuk ekosistem mangrove tidak hanya berfungsi sebagai peredam gelombang tetapi juga sebagai pelindung pantai dari abrasi, penahan lumpur, perangkap sedimen yang diangkut oleh aliran permukaan (run off), serta sebagai daerah asuhan, daerah mencari makanan dan daerah pemijahan bermacam biota perairan baik yang hidup di perairan pantai maupun lepas pantai.

Salah satu indikator dari optimal dan lestarinya kondisi ekosistem mangrove adalah stabilnya struktur dan komposisi serta keanekaragaman flora dan fauna yang dimiliki oleh ekosistem mangrove tersebut (Latupapua, 2011). Salah satu ekosistem mangrove di Sulawesi Tengah terletak di Kabonga Kecil Kabupaten Donggala. Ekosistem tersebut memiliki suhu substrat yang berkisar antara $26^{\circ} \mathrm{C}-$ $30^{\circ} \mathrm{C}$ dan $\mathrm{pH}$ berkisar antara $5,0 \%-6,1 \%$ yang memungkinkan eksistensi kelompok kepiting Uca untuk tumbuh dan berkembang biak dengan kelimpahan relatif maksimum lebih dari 67,65\% (Aprilyanto dkk, 2017) dan meningkatkan pertukaran oksigen dalam sedimen melalui aktifitas bioturbasi (Priosambodo dkk, 2018). Kepiting Uca memiliki peranan penting pada rantai makanan yang berlangsung dalam ekosistem mangrove, karena berperan sebagai pemakan detritus yang menghancurkan serasah pada ekosistem mangrove (Pratiwi, 2010 dalam Aplrilyanto, 2017). Sebagian detritus juga didekomposisi oleh bakteri dan fungi menjadi nutrisi terlarut yang dapat secara langsung dimanfaatkan oleh fitoplankton, alga maupun tumbuhan mangrove itu sendiri dalam proses fotosintesis (Rahman, 2010).

Pemodelan matematika merupakan satu-satunya instrumen yang memungkinkan dilakukannya analisis secara cepat, akurat, murah dan aman. Penelitian terkait interaksi dalam ekosistem mangrove melalui pendekatan model matematika belum banyak dilakukan. Penelitianpenelitian yang dilakukan berfokus pada interaksi vegetasi mangrove dan faktor abiotiknya. Yagi dkk. (2006) telah mengkonstruksi model matematika untuk Mangrove Geo-Ecosystem yang berfokus pada interaksi antara tumbuhan mangrove dan tanah, sedangkan Peracha dkk. (2017) mengkonstruksi model matematika untuk menghitung massa hutan mangrove delta indus untuk mempelajari resesi ekonomi. Lebih lanjut, Nguyen (2011) memperkenalkan model pertumbuhan mangrove yang melibatkan faktor kompetisi, elevasi dan salinitas. Oleh karena itu, penelitian ini menawarkan pendekatan model matematika untuk menggambarkan interaksi yang terjadi antara vegetasi mangrove dengan biota yang berasosiasi dalam ekosistem mangrove, dalam hal ini kepiting Uca. 
Adapun interaksi antar populasi ini berkaitan dengan aliran energi dalam ekosistem mangrove, yakni melalui rantai makanan detritus. Model matematika interaksi populasi dalam ekosistem mangrove akan direpresentasikan oleh sistem persamaan diferensial autonomous nonlinear yang bergantung terhadap variabel waktu. Selanjutnya akan dilakukan analisis dinamik terhadap kestabilan titik ekuilibrium yang menggambarkan koeksistensi populasi yang terlibat dalam ekosistem mangrove.

\section{METODE PENELITIAN}

Model dinamika populasi pada ekosistem mangrove yang menggambarkan interaksi antara dua populasi akan dikaji dalam penelitian ini. Ekosistem mangrove dalam penelitian ini terdiri atas populasi Mangrove (M) dan populasi Kepiting Mangrove (K). Kedua populasi tersebut dikonstruksi dengan mengadaptasi model pertumbuhan logistik. Interaksi antara populasi Mangrove dan populasi Kepiting terjadi melalui rantai makanan detritus.

Selanjutnya, model dinamika populasi pada ekosistem mangrove disajikan ke dalam sistem persamaan diferensial autonomous nonlinear yang bergantung terhadap variabel waktu. Solusi dari model tersebut dikonstruksi menggunakan analisa kualitatif melalui perilaku kestabilan model. Kestabilan model diamati melalui nilai eigen yang diperoleh dari linearisasi di titik ekuilibrium yang menggambarkan koeksistensi dari populasi mangrove dan populasi kepiting.

\section{HASIL DAN PEMBAHASAN}

\subsection{Model dinamika populasi pada ekosistem mangrove}

Model dinamika populasi pada ekosistem mangrove terdiri atas populasi mangrove (M) dan populasi kepiting $(\mathrm{K})$. Kedua populasi tersebut dikonstruksi dengan mengadaptasi model pertumbuhan logistik. Adapun asumsi yang digunakan dalam mengkonstruksi model dinamika populasi pada ekosistem mangrove adalah sebgai berikut:

a. Tidak ada populasi lain dalam ekosistem mangrove selain populasi kepiting dan vegetasi mangrove itu sendiri.

b. Faktor abiotik mendukung pertumbuhan mangrove, sehingga dalam model faktor ini diabaikan.

c. Populasi mangrove dan kepiting berdistribusi seragam.

d. Tidak ada predator bagi populasi kepiting.

e. Aliran energi dalam ekosistem mangrove hanya bersumber dari detritus.

Dalam penelitian ini, interaksi populasi mangrove (M) dan populasi kepiting (K) direpresentasikan oleh parameter $\beta$ dan $\alpha$. Secara rinci, interaksi yang terjadi pada ekosistem mangrove dapat dilihat pada Gambar 1. Deskripsi dari parameter-parameter yang terlibat pada model disajikan dalam Tabel 1. 


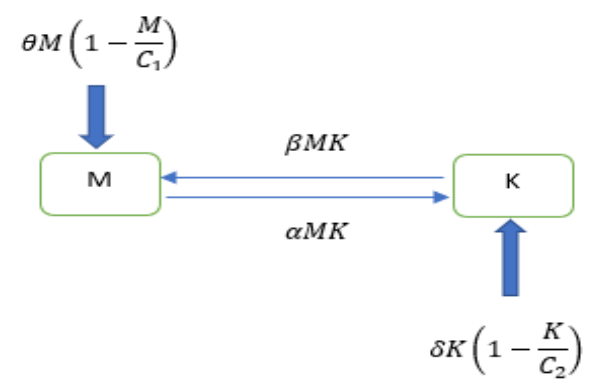

Gambar 1 : Diagram interaksi pada ekosistem mangrove

Dari Gambar 1, model dinamika populasi pada ekosistem mangrove, yang menggambarkan interaksi antara populasi mangrove $(\mathrm{M})$ dan populasi kepiting $(\mathrm{K})$, dapat dituliskan ke dalam sistem persamaan diferensial berikut ini.

$$
\begin{aligned}
& \frac{d M}{d t}=\theta M\left(1-\frac{M}{C_{1}}\right)-\beta M K \\
& \frac{d K}{d t}=\delta K\left(1-\frac{K}{C_{2}}\right)+\alpha M K
\end{aligned}
$$

dengan $\alpha>\beta$, dimana keberadaan mangrove memberikan pengaruh yang lebih besar bagi pertumbuhan kepiting dibandingkan pengaruh kehadiran kepiting bagi pertumbuhan mangrove.

Tabel 1 : Parameter dalam model dinamika populasi pada ekosistem mangrove

\begin{tabular}{|c|l|c|l|}
\hline Parameter & \multicolumn{1}{|c|}{ Deskripsi } & Nilai & \multicolumn{1}{|c|}{ Referensi } \\
\hline$\theta$ & $\begin{array}{l}\text { Laju pertumbuhan intrinsik mangrove per } \\
\text { hari }\end{array}$ & 0.0018 & A Adhi dkk. (2014) \\
\hline$\delta$ & Laju pertumbuhan intrinsik kepiting per hari & 0.003 & $\begin{array}{l}\text { P Andina R. P dan S Ali } \\
(2020)\end{array}$ \\
\hline$C_{1}$ & $\begin{array}{l}\text { Carrying capacity (daya tampung) mangrove } \\
\text { per hektar (ha) }\end{array}$ & 13000 & T Reka dkk (2014) \\
\hline$C_{2}$ & $\begin{array}{l}\text { Carrying capacity (daya tampung) kepiting } \\
\text { per hektar (ha) }\end{array}$ & 250000 & $\begin{array}{l}\text { Kanna dalam H } \\
\text { Muchammad (2010) }\end{array}$ \\
\hline$\alpha$ & Laju interaksi mangrove terhadap kepiting & 0.5 & Asumsi \\
\hline$\beta$ & Laju interaksi kepiting terhadap mangrove & $1 \times 10^{-15}$ & Syarat stabil \\
\hline
\end{tabular}




\subsection{Eksistensi dan kestabilan titik kritis}

Dengan menyelesaikan sistem persamaan diferensial (1)-(2), yang memenuhi $\frac{d M}{d t}=0$ dan $\frac{d K}{d t}=0$, maka dapat diperoleh 4 buah titik kritis yaitu:

$$
\begin{gathered}
T K_{1}=(0,0) \\
T K_{2}=\left(C_{1}, 0\right) \\
T K_{3}=\left(0, C_{2}\right) \\
T K_{4}=\left(\frac{C_{1} \delta\left(C_{2} \beta+\theta\right)}{\delta \theta-C_{1} C_{2} \alpha \beta}, \frac{C_{2} \theta\left(C_{1} \alpha+\delta\right)}{\delta \theta-C_{1} C_{2} \alpha \beta}\right)
\end{gathered}
$$

$T K_{1}$ menggambarkan kepunahan populasi mangrove dan kepiting. Sedangkan titik kritis $T K_{2}$ dan $T K_{3}$ masing-masing menggambarkan kondisi eksistensi salah satu populasi, yaitu mangrove dan kepiting. Selanjutnya $T K_{4}$ menunjukkan kedua populasi mangrove dan kepiting akan eksis dengan syarat $\alpha \beta<\frac{\theta \delta}{C_{1} C_{2}}$.

Kestabilan lokal dari keempat titik kritis tersebut dapat diuji dengan menggunakan analisis nilai eigen dari matriks Jacobian yang dievaluasi pada masing-masing titik kritis. Matriks Jacobian dari sistem persamaan diferensial (1) - (2) adalah sebagai berikut:

$$
J=\left|\begin{array}{cc}
\theta\left(1-\frac{M}{C_{1}}\right)-\theta \frac{M}{C_{1}}+\beta K & \beta M \\
\alpha K & \delta\left(1-\frac{K}{C_{2}}\right)-\delta \frac{K}{C_{2}}+\alpha M
\end{array}\right|
$$

Polinomial karakteristik dari matriks Jacobian yang dievaluasi di titik $T K_{i}, J\left(T K_{i}\right)$, untuk $i=$ $1,2,3,4$, dinyatakan oleh

$$
P(\lambda)=a_{2} \lambda^{2}+a_{1} \lambda+a_{0}
$$

Sehingga diperoleh nilai eigen untuk masing-masing titik kritis adalah sebagai berikut:

1. Untuk $T K_{1}$, diperoleh dua nilai eigen yaitu $\lambda_{1}=\theta$ dan $\lambda_{2}=\delta$. Karena kedua nilai eigen ini bernilai positif maka $T K_{1}$ tidak stabil.

2. Untuk $T K_{2}$, diperoleh dua nilai eigen yaitu $\lambda_{1}=-\theta$ dan $\lambda_{2}=C_{1} \alpha+\delta$. Karena nilai eigen kedua bernilai positif maka $T K_{2}$ tidak stabil.

3. Untuk $T K_{3}$, diperoleh dua nilai eigen yaitu $\lambda_{1}=-\delta$ dan $\lambda_{2}=C_{2} \beta+\theta$. Karena nilai eigen kedua bernilai positif maka dijamin $T K_{3}$ tidak stabil.

4. Untuk $T K_{4}$, diperoleh $a_{0}=\frac{\theta\left(C_{1} \alpha+\delta\right) \delta\left(C_{2} \beta+\theta\right)}{\theta \delta-C_{1} C_{2} \alpha \beta}, a_{1}=\frac{\theta \delta\left(C_{1} \alpha+C_{2} \beta+\delta+\theta\right)}{\theta \delta-C_{1} C_{2} \alpha \beta}$, dan $a_{2}=1$. Berdasarkan kriteria Routh Hurwitz, syarat cukup bagi kestabilan titik kritis $T K_{4}$ adalah dengan menjamin koefisien-koefisien dari polinomial karakteristik $P(\lambda)$ bernilai positif. Sehingga, $a_{1}$, dan $a_{0}$ akan bernilai positif jika $\alpha \beta<\frac{\theta \delta}{C_{1} C_{2}}$. Syarat ini merupakan syarat eksis bagi titik kritis $T K_{4}$. Akibatnya, $T K_{4}$ merupakan titik kritis yang stabil lokal. 


\subsection{Simulasi Numerik}

Pada bagian ini akan ditampilkan simulasi numerik dari model dinamika populasi pada ekosistem mangrove untuk mendukung hasil analitik. Adapun hasil simulasi dengan menggunakan nilai awal $\left(M_{0}, K_{0}\right)=(2,3)$ dan nilai-nilai parameter pada Tabel 1 , dapat dilihat pada Gambar 2. Gambar tersebut menunjukkan bahwa jumlah populasi mangrove terus meningkat hingga 1500 hari dan akan menuju titik kritis koeksistensinya sampai waktu tak hingga. Peningkatan yang terjadi diakibatkan adanya laju pertumbuhan intrinsik mangrove dan laju interaksi dengan kepiting yang memberikan aliran energi bagi mangrove. Begitu pula yang terjadi pada pada populasi kepiting. Seiring dengan berjalannya waktu populasi kepiting mengalami peningkatan yang signifikan selama 1500 hari dan akan menuju titik kritis koeksistensinya sampai waktu tak hingga. Diketahui bahwa pertumbuhan dari populasi kepiting sangat cepat.
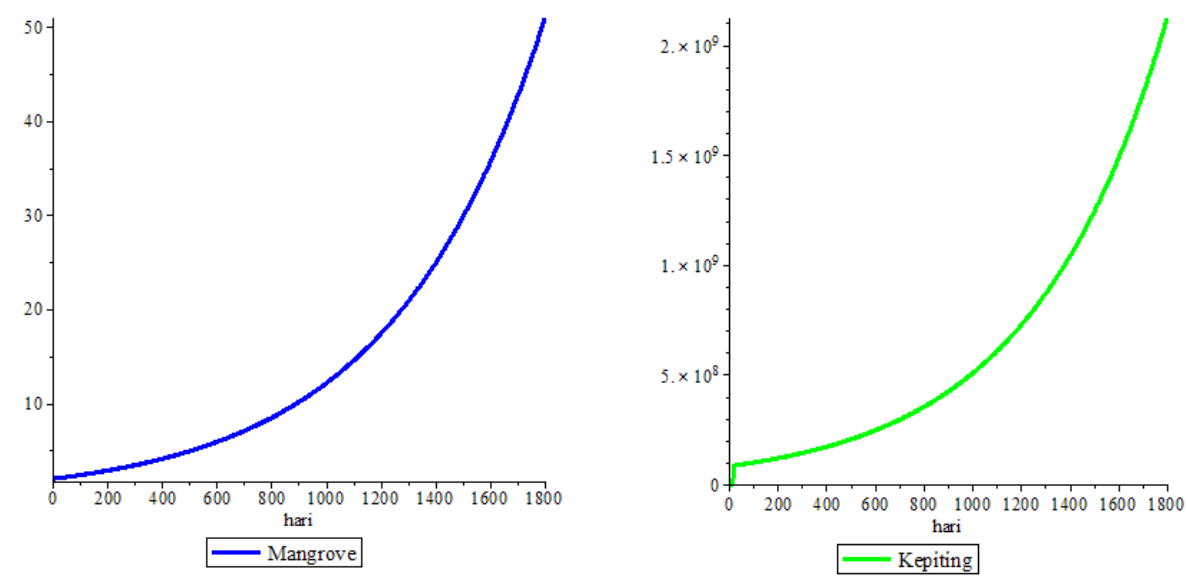

Gambar 2 : Dinamika ekosistem mangrove

\section{KESIMPULAN}

Dalam penelitian ini, kami telah mengkonstruksi model dinamika populasi pada ekosistem mangrove yang melibatkan populasi mangrove dan populasi kepiting Uca. Dari model tersebut, diperoleh empat titik kritis yang dapat dijamin eksistensinya. Titik kritis koeksistensi merupakan satusatunya titik kritis yang dapat dijamin kestabilan lokalnya dengan menetapkan sebuah syarat bagi parameter interaksi yang bergantung pada aspek carrying capacity masing-masing populasi.

\section{DAFTAR PUSTAKA}

[1]. A Adhi, A Zikri dan K Legowo, Studi Pertumbuhan Mangrove pada Kegiatan Rehabilitasi Hutan Mangrove Di Desa Tanjung Limau Kecamatan Muara Badak Kabupaten Kutai Kartanegara. Jurnal Agrifor, Volume XIII Nomor 1, 2014. 
[2]. Aprilyanto D, Fahri dan Annawaty, Kelimpahan relatif dan preferensi habitat pada kepiting mangrove (uca spp.) di Kabonga Kecil, Donggala, Sulawesi Tengah, Natural Science: Journal of Science and Technology, Vol 6 (3): 284 - 290, 2017.

[3]. Nguyen H. A, 2011, A Model For Predicting Mangrove Forest Dynamics Under Variable Environmental Conditions - A Case Study of The Estuary of Dongnai - Saigon River System, Vietnam, Technischen Universität Carolo - Wilhelmina.

[4]. Hasannudin M., Pengaruh Kepadatan Yang Berbeda Terhadap Kecepatan Pergantian Kulit Kepiting Bakau (Scylla Paramamosain) Yang Dipelihara Secara Massal Dalam Karamba, 2010, Skripsi, Fakultas Perikana dan Kelautan Universitas Airlangga.

[5]. Peracha M. A, Hussain M, Khan N, Ali M. L, Shahid M and Mansoor A, Mathematical Model to Quantify the Mass of Mangroves Forest of Indus Delta to Study the Economic Recession, Journal of Multidisciplinary Engineering Science and Technology, Vol. 4 Issue 5, 2017.

[6]. P Andina R. P dan S Ali, Dinamika populasi dan tingkat pemanfaatan Kepiting Bakau (Sylla Serrata Forskal, 1775) Di Perairan kepulauan aru, Maluku. Bawal widya riset Perikanan tangkap, Volume 11 Nomor 3, 2020.

[7]. Priosambodo D dan Evi Erviani A, Spesies dan Mikrohabit Kepiting di Kawasan Mangrove Lantangpeo Kepulauan Tanakeke Sulawesi Selatan, Jurnal IImu Alam dan Lingkungan, 2018, pp59-69.

[8]. Rahman A, Status Ekologi Mangrove untuk Upaya Pengelolaannya di Kawasan Pulau Dua, Kecamatan Kasemen, 2010, Serang, Banten. IPB Bogor.

[9]. Sudarmoyo F. A. S, Nurdiati S dan Sopaheluwakan A, Prediksi Redaman Gelombang Menggunakan Rancangan Drag Tekanan Green Belt Mangrove (GBM) pada Persamaan Air Dangkal (PAD)-Dasar Laut Rata (DLR) dengan Pendekatan Numerik, Journal of Mathematics and Its Applications, Vol 17 No. 2, 2018.

[10]. T Reka, P Arief dan Z Andi, Tingkat Resiliensi Mangrove Berdasarkan Tingkat Bunga Dan Buah Studi Kasus Rhizophora Mucronata Di Desa Dompak, Tangjung Pinang - Kepulauan Riau, Jurnal Umrah, 2015.

[11]. Yagi A, Miyagi T and Hong P. N, A Mathematical model for Mangrove Geo- Ecosystem Focussing on Interactions Between Trees and Soils, Annual Reports of FY 2005, The Core University Program Between Japan Society for the Promotion of Science (JSPS) and Vietnamese Academy of Science and Technology (VAST), P. 285-288, 2006. 